\title{
Effect of Zinc Coating on Delay Nugget Formation in Dissimilar DP600 - AISI304 Welded Joints Obtained by the Resistance Spot Welding Process
}

Mercedes Pérez de la Parte

Univeridad de Oriente

Alejandro Espinel Hernández

Univeridad de Oriente

Mario César Sánchez Orozco ( $\sim$ mario@uo.edu.cu )

Univeridad de Oriente https://orcid.org/0000-0003-1390-9582

Angel Sánchez Roca

Univeridad de Oriente

Emilio Jiménez Macias

Univeridad de Oriente

Julio Blanco Fernández

Univeridad de Oriente

Hipólito Domingo Carvajal Fals

Univeridad de Oriente

\section{Research Article}

Keywords: Resistance spot welding, delay nugget formation, galvanized steel, dissimilar joints, dynamic resistance

Posted Date: November 17th, 2021

DOI: https://doi.org/10.21203/rs.3.rs-1072522/v1

License: (c) (1) This work is licensed under a Creative Commons Attribution 4.0 International License. Read Full License 


\section{Abstract}

This paper researches the effect of zinc coating of galvanized DP600 steel on the dynamic resistance and the delayed nugget formation of dissimilar DP600 - AISI304 welded joints, obtained with resistance spot welding process (RSW). The RSW evaluations consisted of determining, from the dynamic resistance curves, the time involved in the different stages of the process, particularly the beginning of nugget formation. The experimental results showed that, from the dynamic resistance curves, it is possible to identify 8 distinct stages during the welding of galvanized DP600 steel and AISI304 stainless steel. In the case of the welding of uncoated DP600 steel with AISI304, only 6 stages are identified (except for stages 2 and 3 ), which are directly related to the heating, softening and melting of the galvanic coating. The energy used in stages 2 and 3, causes a delay in the beginning of nugget formation for welded joints obtained with galvanized DP600 steel compared to uncoated DP600 - AISI304 welded joints, reaching values between $37.28 \mathrm{~ms}$ and $52.29 \mathrm{~ms}$ for the welding conditions analyzed. Monitoring the time duration of stages 2 and 3 , as defined from the analysis of the dynamic resistance curves, could be used as a tool to predict the beginning of nugget formation in the welding of galvanized steels, to avoid undesirable phenomena such as expulsion and to guarantee the quality of the welded joints.

\section{Introduction}

The development of advanced high strength steels (AHSS) was the response of the steel industry to the demands of the automotive sector in terms of reducing the weight of vehicle structures without compromising their mechanical properties, in addition to other advantages such as cost reduction, safety performance and good weldability [1,2]. Dual-phase (DP) steel is one of the most widely used AHSS in the automotive industry, particularly in the manufacturing of car bodies $[3,4]$.

To increase the lifetime of vehicle structures, it is necessary to protect DP steel from corrosion, mainly with zinc (Zn)-based coatings. Both, Zn-based coated DP steels and uncoated DP steels are predominantly joined by resistance spot welding process (RSW) in the automotive industry due to its high efficiency [5]. Despite the undisputed advantages of the galvanizing process, $\mathrm{Zn}$ coating reduces the weldability of steel [6] and significantly affect RSW parameters and joint properties [7]. Several studies have been conducted to research the influence of the $\mathrm{Zn}$ coating on nugget formation during RSW of galvanized steels [8-10].

Gedeon and Eagar [8], described the mechanisms of nugget formation and growth through an analysis of dynamic inspection data in conjunction with a SEM study. The authors state that the timing of occurrence of fritting, asperity breakdown, formation of molten zinc contacts, substrate softening and indentation, and nugget formation is different in uncoated steels compared to galvanized steels. These occurrences also affect the final shape of the dynamic resistance curves. However, they do not determine the time difference at which these phenomena occur between one material and the other. 
Saha et al. [9], reported the effect of different coating types on nugget formation during RSW of hot pressed forming (HPF) steels. The authors concluded that sheet coating types play an important role in heat generation and nugget formation in RSW of HPF steels. They also state that the nugget growth rate was faster in the Al-Si coating HPF in comparison with the Zn coating HPF, at the initial stage of welding. A comparative analysis between HPF steel with and without coating was not part of the research.

Wei et al. [10] studied the effects of welding and heat treatment parameters on nugget diameter, hardness distribution and tensile shear property of spot welds for similar and dissimilar combinations of galvanized DP1000 and uncoated TRIP980 steels. They concluded that lower melting point and electric resistance of the zinc coating on the DP steel cause an increase in the welding splash current in the order of DP/TRIP, DP/DP and TRIP/TRIP. The authors do not evaluate the influence of the $\mathrm{Zn}$ coating on the nugget development and formation.

Dynamic resistance signals are considered to be closely related to the nugget formation of the spot weld [11-13]. Ma et al. [11], developed a data acquisition system to monitor the RSW process of coated AHSS. The authors argue that when the expulsion occurs, the dynamic resistance, electrode force and displacement experience a sudden drop. They affirm that monitoring and controlling the slope of the resistance curve between the bottom and the highest peak during a specific period is a proper RSW process control strategy. The research was not intended to analyze the influence of the $\mathrm{Zn}$ coating on the RSW process.

Luo et al. [12], analyzed the variation of the dynamic resistance in the welding process of uncoated Q235 steels in order to characterize the nugget growth. They state that the whole nugget growth process is composed of an initial stage, a growing stage and a stable stage, and the curve variations of the three stages indicate the characteristic of nugget growth. The authors concluded that dynamic resistance curves are a useful mean to estimate nugget quality. Although the decomposition of the process into only three stages is useful in the analysis of dynamic resistance curves, these stages may be too general when it comes to analyzing some specific phenomena that occur during the RSW process.

On their part, Ighodaro et al. [13], used the dynamic resistance profiles to study RSW process of Al-Si- and galvannealed (GA)-coated steels. They reported that the dynamic resistance profile for Al-Si- and GAcoated steel are similar. The authors established the existence of an initial heating stage prior to fritting/surface film breakdown, not described by Gedeon and Eagar. They demonstrated that the value of the faying interface resistance could be useful for comparing welding current requirement associated with different coatings since the trend in magnitude of the faying interface resistance correlates directly with the magnitude of the current required for nugget formation for the coated specimens. In this research, the starting time of each of the described stages is not determined, and since the comparative analysis with the uncoated steel is not performed, the delay in the beginning of nugget formation caused by the $\mathrm{Zn}$ coating is not studied either. 
Most of the works previously analyzed have in common the use of similar materials during the welding process. The literature available on the influence of the $\mathrm{Zn}$ coating on the dynamic resistance and nugget formation of dissimilar welded joints of galvanized steels is limited.

Khan et al. [14] conducted dissimilar welding experiments between HSLA350 and DP600 steel, both with zinc coating. They concluded that the physical properties of the DP600 have a predominant role in the microstructure and mechanical properties of the dissimilar joints. The influence of the zinc coating was only evaluated in the analysis of the formation of a relative brittle compound at the edges of the weld nugget.

Jaber et al. [15] analyzed the phase transformations in RSW dissimilar welding between galvanized DP600 steel sheets and AISI430 steel. They reached to the conclusion that the fusion zone is characterized by the dual phase ferrite-martensite microstructure. However, the authors do not analyze the influence of the galvanic coating on the microstructure and mechanical properties of the welded joints.

Lin et al. [16] studied the effects of the zinc coating thickness on the RSW processing of galvanized mild steel samples. They concluded that when the zinc coating thickness increases, the weldability window becomes narrower; however, they do not further study the causes of this behavior.

A few previous works studied DP600 - AISI304 dissimilar welding. Espinel et al. [17], studied the influence of polarity during RSW of dissimilar DP600 steel and AISI 304 stainless steel. The authors concluded that the positions of the sheets (+)DP600/(-)AISI304 and (+)AISI304/(-)DP600), i.e. the polarity, significantly affect the properties of the joint. In this sense, the best mechanical properties were shown by welds made with (+)DP600/(-)AISI304 polarity.

Anijdan et al. [18], studied the effect of current density, welding time, electrodes force and holding time on tensile-shear strength of dissimilar joints DP600/AISI304. They reported the optimal conditions for the parameters based on a model obtained by Taguchi method. The authors did not study the effect of zinc coating, usually used on DP600 steel, in dissimilar welding of these materials.

So, the dissimilar welding of galvanized DP600 steels and AISI304 stainless steel using the RSW process, requires further research. This study is aimed at researching the effect of the zinc coating of galvanized DP600 steel on the dynamic resistance curves and delayed nugget formation in dissimilar DP600 AISI304 welded joints using the RSW process.

\section{Materials And Methods}

\subsection{Materials}

The chemical composition and thermo-physical properties of the parent metal for both steel types are shown in Table 1 and 2, respectively. DP600 steel sheets with a $14 \mu \mathrm{m}$ galvanic coating per side 
(DP600G) was used to study the influence of the presence or not of the Zn coating on the DP600 steel the dynamic resistance curves and delay nugget formation in dissimilar DP600 - AISI304 welded joints.

Table 1. Chemical composition of the base metals, wt-\%.

\begin{tabular}{|llllllllll|}
\hline Material & $\mathbf{C}$ & Mn & Si & S & P & Ni & Cr & Mo & Fe \\
\hline DP600 & 0.11 & 1.6 & 0.182 & - & - & 0.027 & 0.34 & 0.098 & Bal \\
\hline AlSI304 & 0.08 & 2.00 & 1.00 & - & - & 8 & 18 & - & Bal \\
\hline
\end{tabular}

Table 2. Thermophysical properties of the base metals.

\begin{tabular}{|llll|}
\hline Material & $\begin{array}{l}\text { Thermal Conductivity } \\
\left(\mathrm{W} / \mathrm{m}^{\circ} \mathrm{C}\right)\end{array}$ & $\begin{array}{l}\text { Electrical Resistance } \\
(\mu \Omega . \mathrm{m})\end{array}$ & Reference \\
\hline DP600 & 57 & 0.284 & {$[19]$} \\
\hline AISI304 & 14.6 & 0.72 & {$[20]$} \\
\hline
\end{tabular}

\subsection{Welding equipment and procedures}

Resistance spot welds were produced in dual phase steel (DP600) and stainless steel (AISI304) sheets with $1.2 \mathrm{~mm}$ thickness. All welds were made with a medium frequency direct current machine (MFDC) with a welding current (I) between 3 and $5 \mathrm{kA}$, a Bosch PSI6000.100 L controller and a pneumatic clamp with a force of $4 \mathrm{kN}$. The tests were made using water-cooled group A, class I electrodes with $3.5 \mathrm{~mm}$ flat tip ends diameter. During the test, three values of weld time (t): 300,400 and 500 ms were used. The values of the electrode force $(4 \mathrm{kN})$, squeeze time $(4 \mathrm{~s})$, post-weld holding time (100 ms) and up-slope welding current were kept constant.

Considering the results of a previous work [17], the polarities (+) DP600 / (-) AISI304 were selected to obtain the dissimilar welded joints. This polarity presented the best mechanical properties and the highest load capacity. Welded joints were obtained with the combinations DP600/AISI304 and DP600G/AISI304. All welds were randomly performed three times to reduce the experimental error.

\subsection{Dynamic resistance and stages delays determination}

The RSW machine was equipped with a data acquisition system consisting of a National Instrument device NI USB-6009 connected to a PC to record welding current and voltage. The instantaneous voltage across the electrodes was acquired by using probes attached to the electrode holders, and the in-process current signals was captured by a Rogowski toroid sensor attached to bottom electrode. The sampling frequency for the acquisition of the signals was $1.9 \mathrm{kHz}$, and an average digital filtering was applied to signal processing using MATLAB ${ }^{\circledR}$ software. The dynamic resistance is calculated from the acquired voltage and welding current. 
The delay $(\Delta \mathrm{t})$ caused by the zinc coating at the beginning of the welding process stages of DP600G/AISI304 joints was determined as follows:

$\Delta t_{i}=t_{i p p 600}-t_{i p p 600}$

Where $t_{\text {iDP600G }} y t_{i D p 600}$ are the starting times of each stage for DP600G/AISI304 and DP600/AISI304 welded joints, respectively; and $i$ is the stage number $(i=1,4,5,6$ and 7$)$.

\subsection{Metallography}

Metallurgical analysis was conducted using a Leica stereoscope to obtain macrographs of the welded joints. The samples were transversely sectioned, inserted in Bakelite, sanded and polished to a mirror finish. The polished samples were then etched with Vilella's solution during $10 \mathrm{~s}$ and rinsed with running water for about $30 \mathrm{~s}$. For the analysis of the macrographs, digital image processing techniques were applied using the ImageJ $1.48 \mathrm{v}$ software.

Further metallurgical analysis was conducted using an electron microprobe analyzer (EPMA-Jeol-JXA $8230,10 \mathrm{kV}, 10 \mathrm{nA}$ ). The chemical elements distribution in the cross section of the welded joints were analyzed using Wavelength Dispersive Spectrometry (WDS).

\section{Results And Discussion}

\subsection{Dynamic resistance stages}

Figure 1 shows the dynamic resistance curves obtained for two different material combinations, DP600G/AISI304 joint (Zn-based coated DP600 steel) in Fig. 1a and DP600/AISI304 joint (with uncoated DP600 steel) in Fig. 1b, where the Zn effect is evident. The welding condition was the same for both cases $(\mathrm{l}=5 \mathrm{kA}, \mathrm{t}=500 \mathrm{~ms})$.

The dynamic resistance curve shown in Fig. 1a can be separated into 8 distinct stages, based on the models proposed by Gedeon and Eagar [8] and Ighodaro et al. [13], except for some differences that will be further discussed in this study. These stages are described below.

Stage 0 (Surface Heating). This stage was first described by Ighodaro et al. [13]. The increase in resistance experienced at this stage is associated with the heating effect as the current begins to flow causing the surface oxide film breakdown before fritting begins. As can be seen, the initial peak dynamic resistance value is higher for the DP600G/AISI304 joint than for the DP600/AISI304 joint (Fig. 1b). Zn coating on DP600G steel provides additional resistance at the sheet/sheet interface, as well as at the electrode/sheet interface [9]. The time required to reach this peak does not differ much from one case to the other, it was $7.89 \mathrm{~ms}$ and $8.42 \mathrm{~ms}$ for the DP600G/AISI304 and DP600/AISI304 joints, respectively.

Stage 1 (Surface Film Breakdown). The breakdown of the insulating films and the collapse of the asperities due to a complex phenomenon called fritting [8,21], cause a sharp drop in resistance. This fall 
is slightly faster in the case of galvanized DP600 steel (DP600G/AISI304) due to the softness and low melting temperature of zinc (44.21 ms) compared to DP600/AISI304 joint (49.47 ms). During this stage, heating is concentrated in the surface oxide film layer. The end of stage 1 marks the end of the effect of surface oxide film layer.

Stage 2 (Heating and Softening of the Coating). The energy introduced by the RSW process is used in the heating and softening of the $\mathrm{Zn}$ coating at the sheet/sheet and the electrode/sheet interfaces of the DP600G. A small rise in resistance appears as a hump on the dynamic resistance profile $(61.32 \mathrm{~ms})$ caused by some bulk heating that takes place during this stage (Fig. 1a). Due to softening of the coating, the asperity flattening is more pronounced, leading to a net reduction in resistance.

Stage 3 (Coating Melting). At the beginning of this stage $(69.87 \mathrm{~ms})$, the $\mathrm{Zn}$ coating begins to melt at both interfaces. The molten zinc spreads and segregates towards the outer edge of the nugget or even vaporized, increasing the contact surface and causing a reduction in resistance. The decrease in resistance caused by the formation of molten zinc prevents the total resistance from increasing due to the heating of the steel substrate; however, this lasts only a few milliseconds (exactly $8.55 \mathrm{~ms}$ ). At the end of the stage ( $97.89 \mathrm{~ms})$, the iron-to-iron contact at the sheet/sheet interface and the continuous increase in temperature causes the resistance to increase again.

From a comparison of Figures $1 \mathrm{a}$ and $1 \mathrm{~b}$, it can be seen that the resistance curve, using the uncoated DP600 steel (DP600/AISI304 joint), exhibits only the stages 0, 1, 4, 5, 6 and 7, as defined in Fig. $1 \mathrm{a}$. Obviously stages 2 and 3 related to heating, softening and melting of the coating are not present in this case. The bulk heating occurred immediately after oxide film layer breakdown and asperity collapse (Stage 1).

Stage 4 (Bulk Heating). The heating of continue bulk sheets overrides the decrease in contact resistance caused by the molten zinc, this results in a net rise in the dynamic resistance. No melting of the steel substrate has begun at this time and most of the free zinc has been displaced. This stage does not start at the same time in both cases analyzed; there is a delay caused by the presence of the Zn coating on the DP600G/AISI304 joint. For this case (galvanized DP600 steel), stage 4 starts with a delay of $48.42 \mathrm{~ms}$ compared to the DP600/AISI304 joint.

Stage 5 (Bulk Melting). After the displacement of the coating, all the energy introduced by the RSW process is concentrated on the bulk steel substrate. Eventually, the substrate starts melting, which causes an increase in resistance of steel due to the increase in resistivity with melting. The nugget starts to form at the end of this stage, i.e. at $165.30 \mathrm{~ms}$ and $115.80 \mathrm{~ms}$ for DP600G/AISI304 and DP600/AISI304 joints, respectively; 49.50 ms later for galvanized DP600 steel.

In the model proposed by Ighodaro et al. [13][, stages 4 and 5 are presented together as one (Bulk heating/melting), unlike the proposal made in this research where it has been possible to identify and describe separately the bulk heating and bulk melting process. The sum of these two stages ( 4 and 5 ) corresponds to the so-called Bulk Heating/Melting stage. 
Stage 6 (Nugget Growth). Immediately after the beginning of nugget formation, there was a gradual elimination of sheet/sheet interface resistance, which contributed to the reduction of the resistance. But, simultaneously, the melting causes an increase in resistance resulting from the higher resistance of the liquid metal formed, as explained above. Due to the opposite directions of these two effects, there may be no obvious change in the dynamic resistance profile. The temperature in the process starts to stabilize and nugget growth plays a dominant role [14].

Stage 7 (Expulsion). When the nugget diameter grows larger than the effective electrode diameter, the phenomenon of expulsion occurs. The dynamic resistance will decrease sharply due primarily to the abrupt loss of material thickness and extreme indentation [8]. As in previous stages, the expulsion phenomenon occurs later in the case of the DP600G/AISI304 joint (at $488.45 \mathrm{~ms}$ ) with respect to the DP600/AISI304 joint (437.57 ms). This situation can be caused by excessive current or weld time. Expulsion is generally undesirable due to loss of joint strength caused by loss of material.

The 7 different stages into which the RSW process is divided from the behavior of the dynamic resistance values have been described in this section. It can be seen that the two different combinations of materials (DP600G/AISI304 and DP600/AISI304) produces different dynamic resistance profiles, in relation to the number of stages, demonstrating the effect of the zinc coating on the dynamic resistance curves. These stages show the characteristics of nugget formation, which is a useful means of estimating nugget quality. Table 3 summarizes the welding time values corresponding to the beginning of the stages described above.

Table 3

Welding time at the beginning of process stages.

\begin{tabular}{|lllllllll|}
\hline & $\mathrm{t}_{0}$ & $\mathrm{t}_{1}$ & $\mathrm{t}_{2}$ & $\mathrm{t}_{3}$ & $\mathrm{t}_{4}$ & $\mathrm{t}_{5}$ & $\mathrm{t}_{6}$ & $\mathrm{t}_{7}$ \\
& $(\mathrm{~ms})$ & $(\mathrm{ms})$ & $(\mathrm{ms})$ & $(\mathrm{ms})$ & $(\mathrm{ms})$ & $(\mathrm{ms})$ & $\begin{array}{l}(\mathrm{ms}) \\
(\mathrm{ms})\end{array}$ \\
\hline DP600G/AISI304 & 0.00 & 7.89 & 44.21 & 69.87 & 97.89 & 148.40 & 165.30 & 488.45 \\
\hline DP600/AISI304 & 0.00 & 8.42 & - & - & 49.47 & 100.00 & 115.80 & 437.57 \\
\hline
\end{tabular}

As shown in Table 3, the presence of the Zn coating on the DP600G steel has a significant influence on the time needed for the start of nugget formation and for the occurrence of the expulsion. The effect of zinc coating on delay nugget formation will be further discussed below.

\subsection{Effect of welding current on nugget growth}

Figure 2 shows the dynamic resistance curves for DP600G/AISI304 and DP600/AISI304 welded joints at different welding current values and a constant welding time of $500 \mathrm{~ms}$, indicating the effect of welding current on nugget growth.

Figure 2 shows that the size of the nugget growths with the increase of the current intensity due to the Joule effect, which corroborates what has been stated by other authors. [22-24]. As the welding current 
increases, more energy is provided to the nugget growth. It can also be verified that the nugget diameter was smaller for the welded joints of the galvanized DP600 steel (DP600G/AISI304). By subjecting the galvanized steel to a high rate of heat input, the low melting point of the zinc $(419 \circ \mathrm{C})$ provoked the galvanic coating to be displaced from the center towards the periphery of the contact area. The resulting unstable geometry of the $\mathrm{Zn}$ coating leads to a lower and unstable interfacial resistance, so that more energy is required to increase the process temperature as reported by Lin et al [16].

Furthermore, when the welding current increases, the maximum values of the dynamic resistance curves decrease. This behavior is caused by two fundamental reasons: first, a high current results in a low resistance due to a constant film breakdown voltage. Second, a higher current results in a higher heating rate, which softens and flattens the asperities more quickly, causing the resistance to start dropping from relatively low values [13].

The time values corresponding to the beginning of the stages explained in the previous section are smaller as the current increases, which also indicates that the nugget growth rate is higher. The curves of dynamic resistance show some similarity between one another, but for welding current values of $3 \mathrm{kA}$ it may be difficult to identify the stages described above.

\subsection{Effect of zinc coating on delay nugget formation}

Figure 3 shows the dynamic resistance curves for DP600G/AISI304 and DP600/AISI304 joints, for a welding condition I $=5 \mathrm{kA}$ and $\mathrm{t}=500 \mathrm{~ms}$; where the delay $(\Delta \mathrm{t})$ introduced in the different stages of the process by the Zn coating of galvanized DP600 steel can be observed.

It can be observed in Fig. 3, that the value of the initial peak dynamic resistance is higher for the DP600G/AISI304 joint compared to the DP600/AISI304 joint, this result is in agreement with that stated by Saha et al. [9]. As explained above, the coating layer provides additional resistance at both interfaces (sheet/sheet and electrode/sheet interfaces); therefore, the time required to reach this peak $\left(\Delta t_{1}\right)$ is 0.53 ms higher for the galvanized DP600 steel.

During the formation of the nugget in the DP600G/AISI304 welded joint, two stages (stages 2 and 3) take place. These stages are closely related to the heating, softening and melting of the coating. This is not the case for the DP600/AISI304 joint, where no coating is present. The total duration of these two stages was $53.68 \mathrm{~ms}$. The energy used during stages 2 and 3 causes nugget formation for the galvanized DG600 steel to be reached after a longer time compared to the uncoated DP600 steel. This time lag in the beginning of nugget formation is called delay $\left(\Delta \mathrm{t}_{6}\right)$, and it reaches a value of $49.50 \mathrm{~ms}$ for this experimental condition.

Figure 3 also shows that the delay caused by the Zn coating not only affects the beginning of nugget formation (stage 6), but also other stages such as stage 4 (Bulk Heating), stage 5 (Beginning of Substrate Melting) and stage 7 (Expulsion). Table 4 shows a summary of the delay values at the beginning of each stage, determined by equation 1 . 
Table 4

Delay introduced by the $\mathrm{Zn}$ coating at the beginning of RSW process stages.

\begin{tabular}{|llllll|}
\hline & $\Delta \mathrm{t}_{1}$ & $\Delta \mathrm{t}_{4}$ & $\Delta \mathrm{t}_{5}$ & $\Delta \mathrm{t}_{6}$ & $\Delta \mathrm{t}_{7}$ \\
& $(\mathrm{~ms})$ & $(\mathrm{ms})$ & $(\mathrm{ms})$ & $(\mathrm{ms})$ & $(\mathrm{ms})$ \\
\hline Delay & 0.53 & 48.42 & 48.40 & 49.50 & 50.88 \\
\hline
\end{tabular}

Table 4 shows the delay value $\left(\Delta \mathrm{t}_{4}=48.42 \mathrm{~ms}\right)$ introduced by the heating, softening and melting of the coating, i.e., stages 2 and 3 , in the case of DP600G/AISI304 joints, remains practically unchanged until the end of the RSW process $\left(\Delta t_{7}=50.88 \mathrm{~ms}\right)$ for this experimental condition $(\mathrm{I}=5 \mathrm{kA}, \mathrm{t}=500 \mathrm{~ms})$. From this result, it can be stated that the time duration of stages 2 and 3 , as defined from the analysis of the dynamic resistance curves, could be used as a tool to predict the beginning of nugget formation, avoid undesirable phenomena such as expulsion and guarantee the quality of welded joints in galvanized steels. A similar analysis was performed for the rest of the welding conditions resulting in delay values ranging from $48 \mathrm{~ms}$ to almost $150 \mathrm{~ms}$, depending on the experimental condition, as shown in Fig. 4.

Figure 4a shows the nugget diameter versus time curves obtained from the average nugget diameter values for each experimental condition. For the parameter set of $3 \mathrm{kA}$ and $300 \mathrm{~ms}$, the nugget diameter value shown is zero as no DP600G/AISI304 welded joints were achieved for this condition. The crosssectional macrographs of to two experimental conditions: 5 kA, 300 ms, DP600/AISI304 (Fig. 4b) and 5 kA, 370 ms, DP600G/AISI304 (Fig. 4c) are also shown, the latter corresponding to an additional experimental condition performed as confirmation test.

Figure 4a shows the average nugget diameter value $(4.69 \mathrm{~mm})$ obtained for the experimental condition of $5 \mathrm{kA}$ and $300 \mathrm{~ms}$ for DP600/AISI304 welded joints. It is evident that to achieve the same nugget diameter for the DP600G/AISI304 welded joints it would be necessary to prolong the process by $70 \mathrm{~ms}$ (intersection point). A confirmation test was made with the values obtained at the intersection point shown in Figure 4a. The results of the confirmation test are shown in Table 5.

Table 5

Confirmation test results (DP600G/AISI304 welded joint).

\begin{tabular}{|lccc|}
\hline Experiment & I (kA) & $\begin{array}{l}\text { t } \\
(\mathrm{ms})\end{array}$ & $\begin{array}{l}\text { Nugget diameter } \\
(\mathrm{mm})\end{array}$ \\
\hline Theoretical result * & 5 & 370 & 4.69 \\
\hline Average confirmation test result & 5 & 370 & 4.57 \\
\hline Percentage error (\%) & & & 2.56 \\
\hline * Values corresponding to the intersection point (Fig. 4a)
\end{tabular}


Confirmation experimentation was performed using the theoretical results obtained from the intersection point shown in Fig. 4a. Three runs were performed with the welding current values of $5 \mathrm{kA}$ and welding time of $370 \mathrm{~ms}$. Based on the results, it was found that the average nugget diameter confirmation test result was close to the theoretical result. The percentage error between the theoretical result and the average result of the confirmation test was calculated. The percentage error was within the acceptance range.

Figures $4 \mathrm{~b}$ and $4 \mathrm{c}$ show the cross-sectional macrographs of the experimental conditions: $5 \mathrm{kA}, 300 \mathrm{~ms}$, DP600/AISI304 and 5 kA, 370 ms, DP600G/AISI304, respectively. Based on the comparative analysis between both macrographs, the need to increase the energy input to obtain welded joints using galvanized DP600 steel becomes evident, that is, if nugget sizes similar to the welded joints with uncoated DP600 steels are to be achieved.

In Fig. 4c, the formation of an asymmetrical nugget can also be observed. The asymmetry of the nugget, characterized by mayor penetration on the side of the AISI304 plate, is a consequence of the difference between the thermal conductivity and electrical resistivity of two steel sheets. Similar results were obtained by Marashi et al [25].

\subsection{Metallurgical analysis results}

To corroborate the fact that, as explained above, Zn coating in galvanized DP600 steel segregates towards the outer edge of the nugget, or it is even vaporized at the end of stage 3 of the process," metallurgical analyses were conducted. Fig. 5 shows the chemical element line scanning of the WDS analysis performed on the cross section of one of the DP600G/AISI304 solder joint samples obtained for $5 \mathrm{kA}$ and $500 \mathrm{~ms}$. The analyzed welded joint is composed of $\mathrm{Fe}$, with a higher concentration in the DP600G base metal region of $\mathrm{Fe}, \mathrm{Ni}$ and $\mathrm{Cr}$ in the nugget, as a result of the contribution of the AISI304 stainless steel and a third region with higher presence of $\mathrm{Cr}$ and Ni corresponding to the AISI304 base metal.

As shown in Fig. 5, no Zn presence was found in the nugget of the welded joint, which demonstrates that the galvanic coating was vaporized or segregated in the liquid state towards the edges of the nugget during the RSW process.

\section{Conclusions}

- The analysis of the dynamic resistance curves identified 8 distinct stages during the welding of the dissimilar materials: galvanized DP600 steel and AISI304 stainless steel (DP600G/AISI304 joints). The stages are: surface heating, surface film breakdown; heating and softening of the coating, coating melting, bulk heating, bulk melting, nugget growth and expulsion, in that order.

- The dynamic resistance curves obtained for the welding of uncoated DP600 steel and AISI304 stainless steel (DP600/AISI304 joints), do not present the stages 2 and 3: the heating and softening 
of coating stage and the coating melting stage. Therefore, once the surface film breakdown stage is finished, the bulk heating stage begins, immediately followed by the bulk melting stage.

- The energy used during stages 2 and 3 causes a delay in the beginning of nugget formation for DP600G/AISI304 joints (with galvanized DP600 steel) compared to DP600/AISI 304 joints (uncoated DP600 steel). This delay reaches a value of $48.42 \mathrm{~ms}$ and remains practically unchanged during the rest of the RSW process for a welding current of $5 \mathrm{kA}$ and time of $500 \mathrm{~ms}$. In a similar analysis performed for the rest of the experimental conditions, delay values between 48 and $150 \mathrm{~ms}$ were obtained.

- The control of the time duration of stages 2 and 3 , as defined from the analysis of the dynamic resistance curves, could be used as a tool to predict the beginning of nugget formation in the welding of galvanized steels, to avoid undesirable phenomena such as expulsion and to guarantee the quality of the welded joints.

\section{Declarations}

\section{Acknowledgments}

The authors give thanks to the Universidad de Oriente and Universidad de la Rioja for their financial and infrastructure support for the development of this research

\section{References}

1. Pouranvari M, Marashi S, Mousavizadeh S (2011) Dissimilar resistance spot welding of DP600 dual phase and AISI 1008 low carbon steels: correlation between weld microstructure and mechanical properties. Ironmaking \& Steelmaking 38 (6):471-480

2. Zhao J, Jiang Z (2018) Thermomechanical processing of advanced high strength steels. Progress in Materials Science 94:174-242

3. Hayat F, Sevim i (2012) The effect of welding parameters on fracture toughness of resistance spotwelded galvanized DP600 automotive steel sheets. The International Journal of Advanced Manufacturing Technology 58 (9-12):1043-1050

4. Verma R, Arora KS, Sharma L, Chhibber R (2021) Experimental investigation on resistance spot welding of dissimilar weld joints. Proceedings of the Institution of Mechanical Engineers, Part E: Journal of Process Mechanical Engineering 235 (2):505-513

5. Tumuluru M (2007) The effect of coatings on the resistance spot welding behavior of $780 \mathrm{MPa}$ dualphase steel. WELDING JOURNAL-NEW YORK- 86 (6):161

6. Kalashami AG, Han X, Goodwin F, Zhou NY (2020) The influence of modified annealing during the galvanizing process on the resistance spot welding of the $\mathrm{CMn1}$. 8Si advanced high strength steel. 
Surface and Coatings Technology 381:125181

7. Ertek Emre H, Kaçar R (2016) Resistance spot weldability of galvanize coated and uncoated TRIP steels. Metals 6 (12):299

8. Gedeon S, Eagar T (1986) Resistance spot welding of galvanized steel: Part II. Mechanisms of spot weld nugget formation. Metallurgical Transactions B 17 (4):887-901

9. Saha D, Ji C, Park Y (2015) Coating behaviour and nugget formation during resistance welding of hot forming steels. Science and Technology of Welding and Joining 20 (8):708-720

10. Wei ST, Lv D, Liu RD, Lin L, Xu RJ, Guo JY, Wang KQ (2014) Similar and dissimilar resistance spot welding of advanced high strength steels: welding and heat treatment procedures, structure and mechanical properties. Science and Technology of Welding and Joining.

doi:10.1179/1362171814Y.0000000211

11. Ma C, Bhole S, Chen D, Lee A, Biro E, Boudreau G (2006) Expulsion monitoring in spot welded advanced high strength automotive steels. Science and Technology of Welding and Joining 11 (4):480487

12. Luo Y, Rui W, Xie X, Zhu Y (2016) Study on the nugget growth in single-phase AC resistance spot welding based on the calculation of dynamic resistance. Journal of Materials Processing Technology 229:492-500

13. Ighodaro OL-R, Biro E, Zhou YN (2017) Study and applications of dynamic resistance profiles during resistance spot welding of coated hot-stamping steels. Metallurgical and Materials Transactions A 48 (2):745-758

14. Khan M, Bhole S, Chen D, Biro E, Boudreau G, Van Deventer J (2009) Welding behaviour, microstructure and mechanical properties of dissimilar resistance spot welds between galvannealed HSLA350 and DP600 steels. Science and Technology of Welding and Joining 14 (7):616-625

15. Jaber HL, Pouranvari M, Marashi SPH, Alizadeh-Sh M, Salim RK, Hashim FA (2014) Dissimilar spot welding of dual phase steel/ferritic stainless steel: phase transformations. Science and Technology of Welding and Joining 19 (7):565-571. doi:doi:10.1179/1362171814Y.0000000226

16. Lin H, Hsu C, Lee C, Kuo T, Jeng S (2018) Effects of zinc layer thickness on resistance spot welding of galvanized mild steel. Journal of Materials Processing Technology 251:205-213

17. Espinel Hernández A, Sánchez Roca A, Carvajal Fals H, Ferraresi VA, Oliveira Vilarinho L (2016) Influence of Polarity on Mechanical Properties of Dissimilar Resistance Spot Welds of DP 600/AISI 304 steels. Science and Technology of Welding and Joining. doi:10.1080/13621718.2016.1149913 
18. Anijdan SM, Sabzi M, Ghobeiti-Hasab M, Roshan-Ghiyas A (2018) Optimization of spot welding process parameters in dissimilar joint of dual phase steel DP600 and AISI 304 stainless steel to achieve the highest level of shear-tensile strength. Materials Science and Engineering: A 726:120-125

19. Zhao D, Wang Y, Zhang P, Liang D (2019) Modeling and experimental research on resistance spot welded joints for dual-phase steel. Materials 12 (7):1108

20. Chu T, Ho C (1978) Thermal conductivity and electrical resistivity of eight selected AISI stainless steels. In: Thermal Conductivity 15 . Springer, pp 79-104

21. Tan W, Zhou Y, Kerr H, Lawson S (2004) A study of dynamic resistance during small scale resistance spot welding of thin Ni sheets. Journal of Physics D: Applied Physics 37 (14):1998

22. Jagadeesha T, Jothi TS (2015) Studies on the influence of process parameters on the AISI 316L resistance spot-welded specimens. The International Journal of Advanced Manufacturing Technology:116

23. Safari M, Mostaan H, Kh HY, Asgari D (2016) Effects of process parameters on tensile-shear strength and failure mode of resistance spot welds of AISI 201 stainless steel. The International Journal of Advanced Manufacturing Technology:1-11

24. Wan X, Wang Y, Zhang P (2014) Modelling the effect of welding current on resistance spot welding of DP600 steel. Journal of Materials Processing Technology

25. Marashi P, Pouranvari M, Amirabdollahian S, Abedi A, Goodarzi M (2008) Microstructure and failure behavior of dissimilar resistance spot welds between low carbon galvanized and austenitic stainless steels. Materials science and engineering: A 480 (1):175-180

\section{Figures}



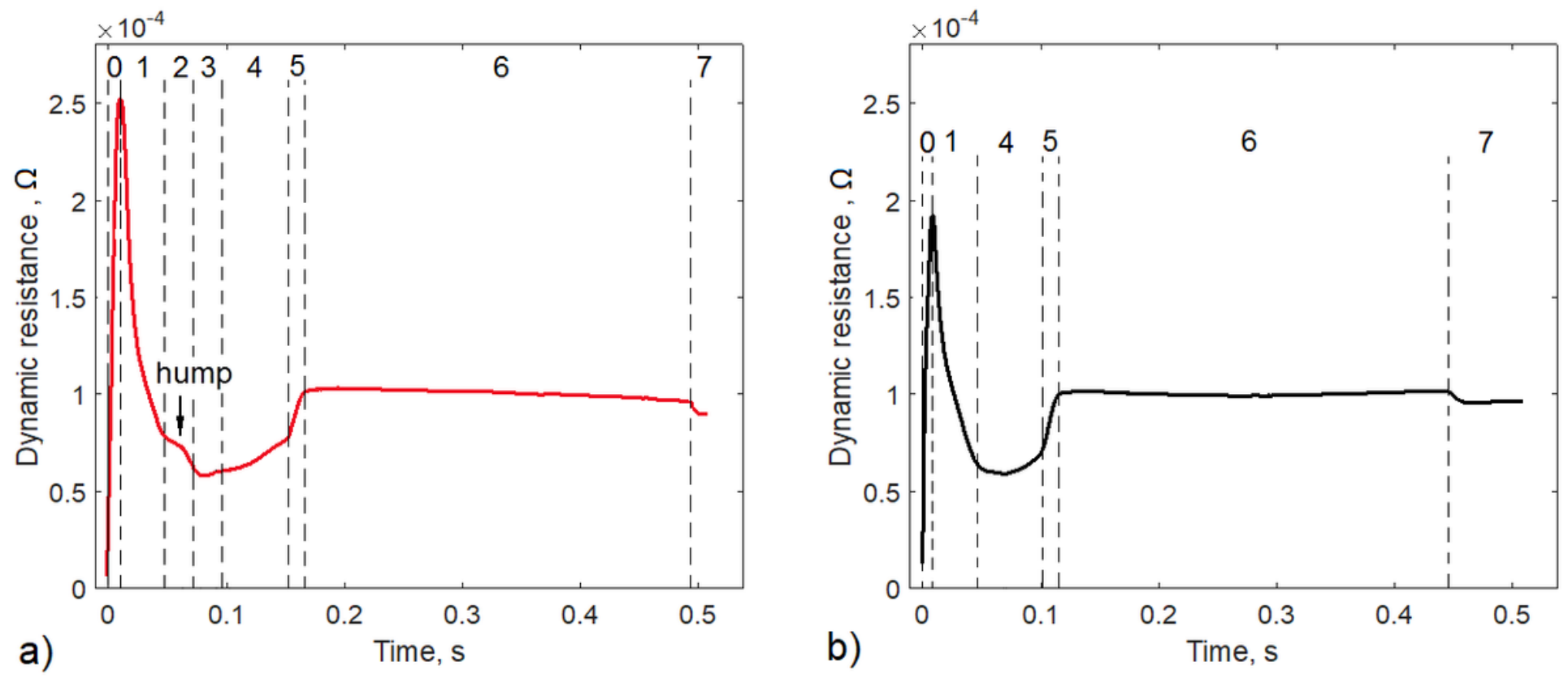

Figure 1

Dynamic resistance curves. a) DP600G/AISI304; b) DP600/AISI304. 

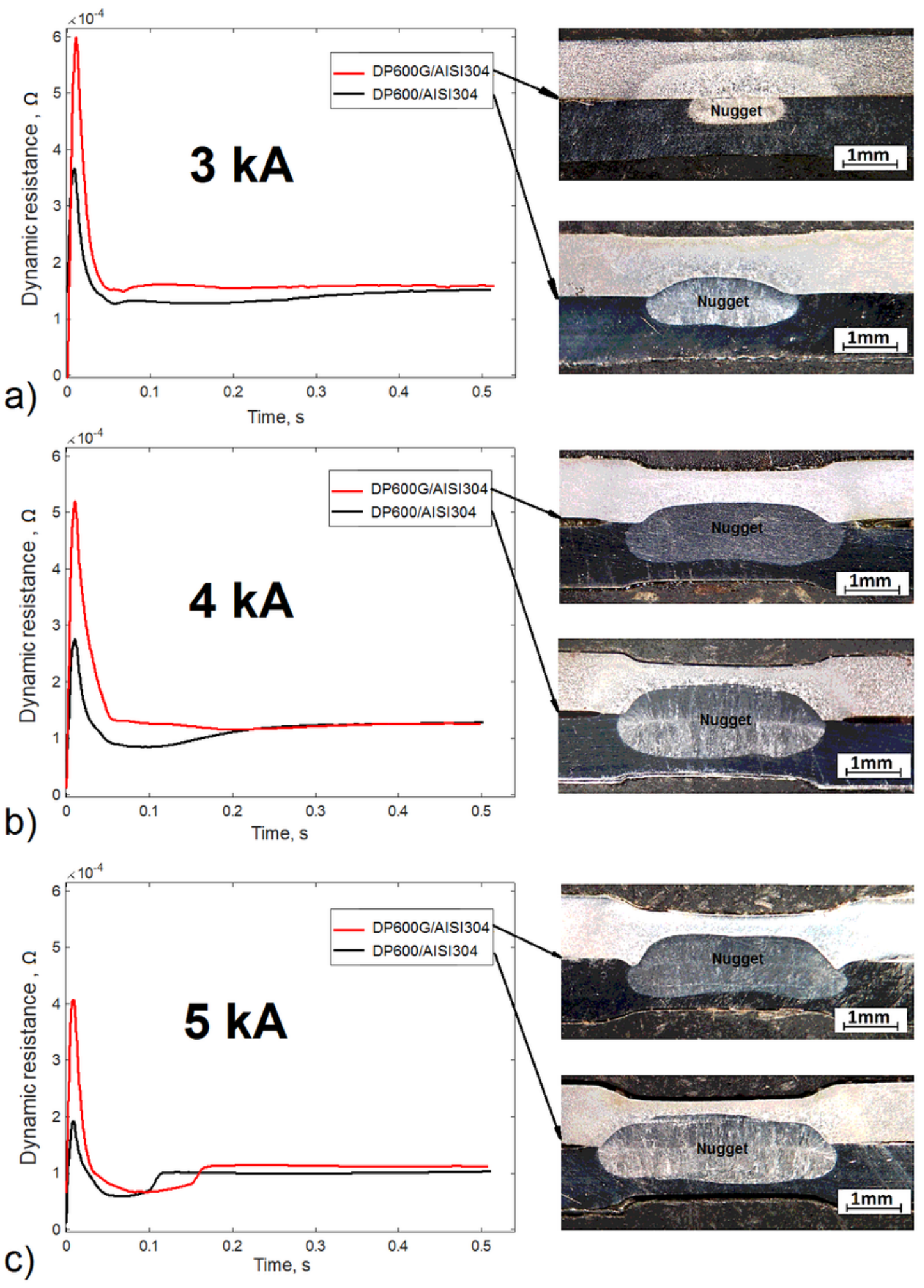

Figure 2

Curves of dynamic resistance for DP600G/AISI304 and DP600/AISI304 joints welded by different welding current. a) $3 \mathrm{kA}$; b) $4 \mathrm{kA}$ and c) $5 \mathrm{kA}$. 


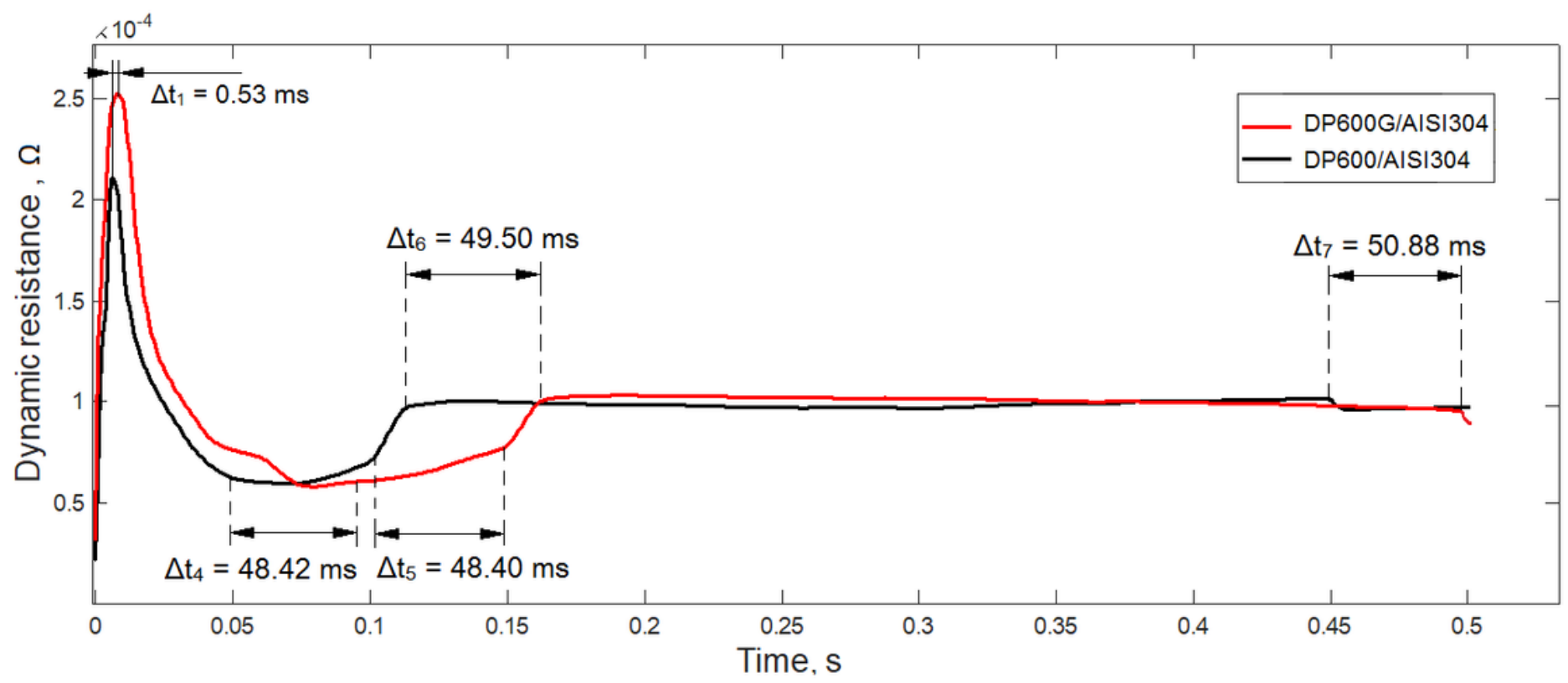

Figure 3

Delay introduced in RSW process stages 1, 4, 5, 6 and 7 by the Zn coating of galvanized DP600 steel. 


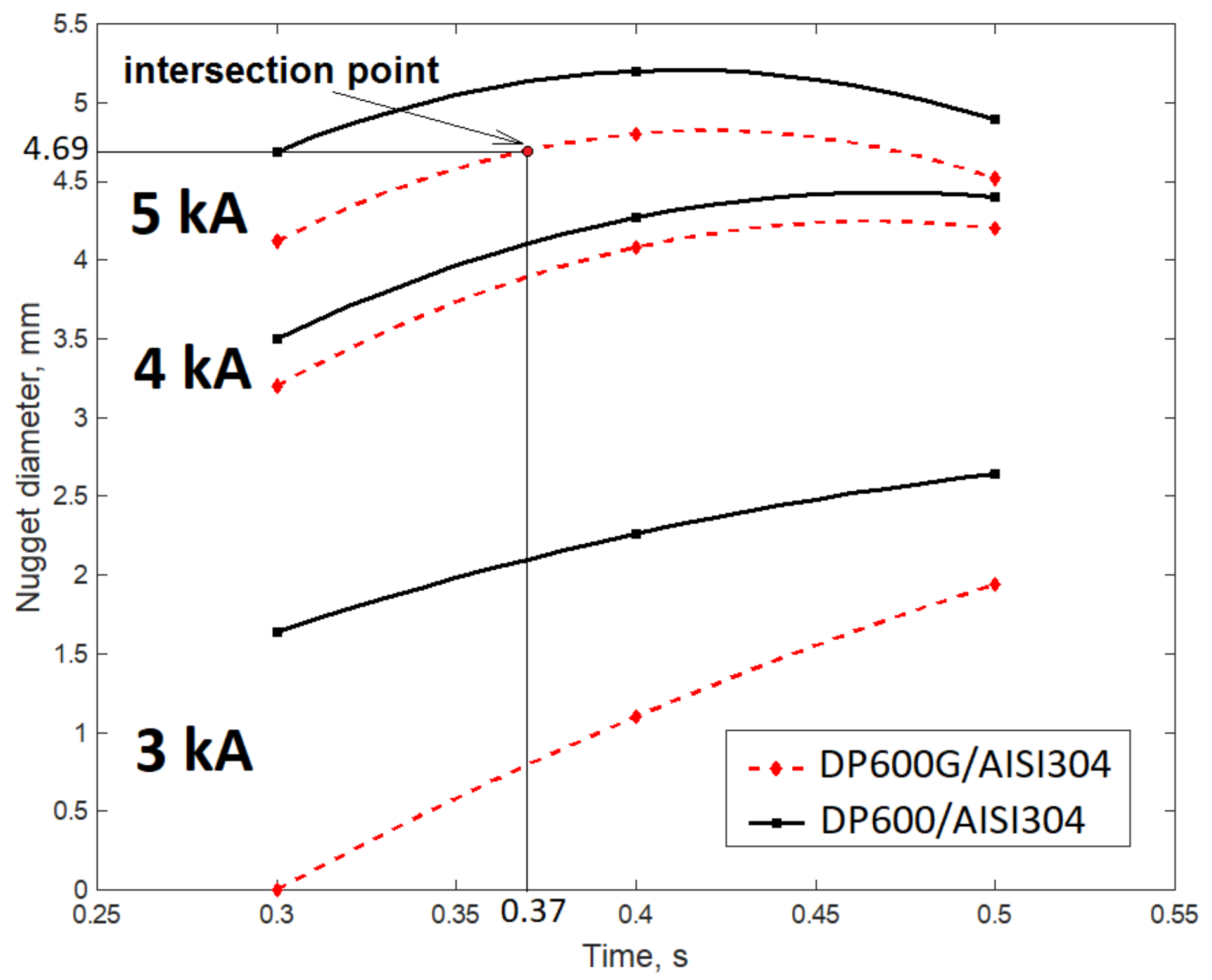

Figure 4

a) Nugget diameter versus time curves and Macrographs of cross sections for conditions: b) $5 \mathrm{kA}, 300$ ms, DP600/AISI304 and c) 5 kA, 370 ms, DP600G/AISI304 (confirmation test). 


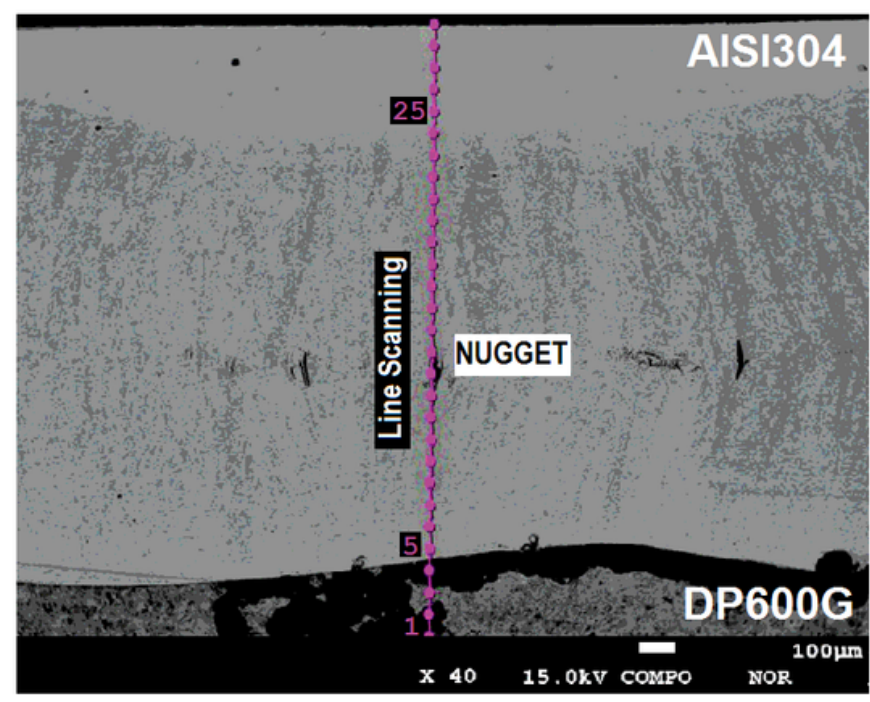

\begin{tabular}{|c|c|c|c|c|c|}
\hline & $\mathrm{Fe}$ & $\mathrm{Si}$ & $\mathrm{Cr}$ & $\mathrm{Ni}$ & \multirow{4}{*}{ DP600G } \\
\hline 1 & 100.00 & & & & \\
\hline 2 & 100.00 & & & & \\
\hline 3 & 100.00 & & & & \\
\hline 4 & 100.00 & & & & \\
\hline 5 & 80.56 & 0.33 & 13.19 & 5.93 & \\
\hline 6 & 80.53 & 0.37 & 13.36 & 5.75 & \\
\hline 7 & 79.92 & 0.32 & 13.21 & 6.54 & \\
\hline 8 & 80.94 & & 13.04 & 6.02 & \\
\hline 9 & 80.58 & 0.27 & 13.11 & 6.04 & \\
\hline 10 & 80.04 & & 13.79 & 6.17 & \\
\hline 11 & 80.64 & 0.31 & 13.19 & 5.86 & \\
\hline 12 & 80.31 & 0.21 & 13.42 & 6.06 & \\
\hline 13 & 79.91 & 0.31 & 13.71 & 6.06 & \\
\hline 14 & 81.18 & 0.24 & 12.91 & 5.67 & \\
\hline 15 & 79.96 & 0.33 & 13.17 & 6.54 & \\
\hline 16 & 80.08 & 0.24 & 13.28 & 6.40 & \\
\hline 17 & 79.10 & 0.35 & 13.93 & 6.61 & \\
\hline 18 & 80.84 & 0.30 & 13.42 & 5.44 & NUGGET \\
\hline 19 & 81.33 & 0.37 & 13.04 & 5.26 & \\
\hline 20 & 81.29 & 0.30 & 12.88 & 5.53 & \\
\hline 21 & 79.53 & 0.32 & 13.69 & 6.46 & \\
\hline 22 & 80.54 & 0.27 & 13.07 & 6.12 & \\
\hline 23 & 80.42 & 0.27 & 13.48 & 5.83 & \\
\hline 24 & 79.96 & 0.27 & 13.39 & 6.38 & \\
\hline 25 & 71.47 & & 19.42 & 8.88 & \\
\hline 26 & 71.33 & 0.36 & 19.50 & 8.82 & \\
\hline 27 & 71.22 & 0.42 & 19.78 & 8.59 & AISI304 \\
\hline 28 & 71.23 & 0.49 & 19.78 & 8.51 & \\
\hline 29 & 71.27 & 0.45 & 19.81 & 8.48 & \\
\hline
\end{tabular}

a)

b)

Figure 5

WDS analysis: a) Macrostructure of the cross section and b) Element line scanning results (Condition: I = $5 \mathrm{kA}, \mathrm{t}=500 \mathrm{~ms}$ ) 